\title{
Erratum to: Electromagnetic modeling of carbon-fiber reinforced composite materials using the wave digital concept
}

\author{
Slimane Rezgui ${ }^{1} \cdot$ Hassane Mohellebi $^{1}$. \\ Mouloud Féliachi ${ }^{2}$
}

Published online: 15 February 2017

(C) Springer Science+Business Media New York 2017

\section{Erratum to: Multidim Syst Sign Process DOI 10.1007/s11045-016-0467-3}

Unfortunately, a superscript letter was not displayed correctly in Eq. 31, and correct version of Fig. 27 was not used in an earlier version of the original publication. The corrected versions of Eq. 31 and Fig. 27 are published with this erratum. Also, the original version was updated.

$$
0<C F L=\frac{v_{\max } T}{X} \leq \frac{1}{\sqrt{2}}=0.7071,
$$

(a)

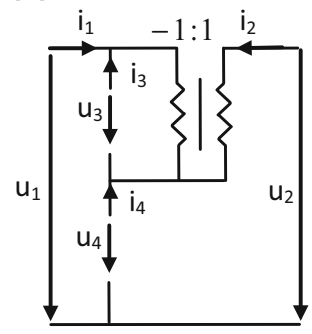

(b)

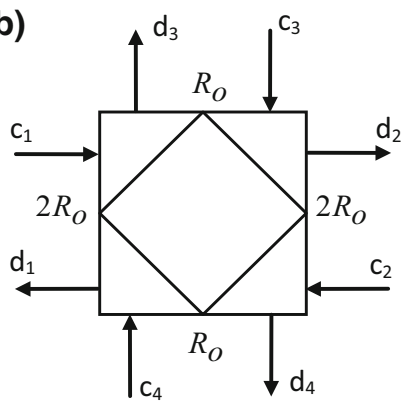

Fig. 27 a Four-port symmetric Jaumann structure used in Fig. 2; b Its corresponding differential adaptor

The online version of the original article can be found under https://doi.org/10.1007/s11045-016-0467-3.

Slimane Rezgui
rzg90@yahoo.fr

1 Faculté de Génie Électrique et Informatique, Université Mouloud Mammeri de Tizi ouzou, BP 17 RP, 1500 Tizi ouzou, Algeria

2 Laboratoire IREENA, CRTT, IUT Saint-Nazaire, Université de Nantes, Boulevard de l'université, BP 406, 44602 Saint-Nazaire Cédex, France 